\title{
Aspirin Dosis Rendah Efektif Menurunkan Resistensi Arteri Uterina yang Abnormal pada Ibu Hamil Usia Kehamilan 16-24 Minggu
}

\author{
Low Dose Aspirin is Effective in Reducing Abnormal Uterine Artery Resistance in Pregnant \\ Women with Gestational Age 16-24 Weeks
}

\author{
Rachmi, Agus Sulistyono \\ Departemen Obstetri dan Ginekologi, Fakultas Kedokteran, \\ Universitas Airlangga, RSUD Dr Soetomo, Surabaya
}

\begin{abstract}
ABSTRAK
Tujuan: mengetahui pengaruh pemberian aspirin $125 \mathrm{mg} / \mathrm{hari}$ terhadap penurunan resistensi pembuluh darah arteri uterina pada ibu hamil USG doppler velocimetry arteri uterina abnormal usia kehamilan 16-24 minggu.

Bahan dan Metode: Penelitian ini merupakan penelitian praeksperimental pre-test post-test one group design. Subjek penelitian adalah ibu hamil dari puskesmas Mulyorejo dan Kalijudan Surabaya, usia kehamilan 16-24 minggu dengan hasil USG doppler velocimetry arteri uterina abnormal. Pemeriksaan USG doppler arteri uterina dilakukan di Departemen/SMF Obstetri Ginekologi Fakultas Kedokteran Universitas AirlanggaRSUD Dr. Soetomo, divisi Feto-Maternal, sebelum dan sesudah pemberian aspirin $125 \mathrm{mg} / \mathrm{hari}$ selama 4 minggu. Hasil pemeriksaan USG doppler velocimetry arteri uterina dibagi menjadi empat tingkatan yaitu; normal bila RI $\leq 0,58$ tanpa adanya notching, tingkat I jika RI > 0,58 tanpa adanya notching, tingkat II RI $\leq 0,58$ disertai notching dan tingkat III bila RI $>0,58$ disertai adanya notching.

Hasil: Dari 99 subjek penelitian dengan hasil USG doppler velocimetry arteri uterina abnormal yaitu; 81 orang tingkat I, 2 orang tingkat II dan 16 orang tingkat III. Hasil pemeriksaan USG doppler velocimetry arteri uterina setelah diberikan aspirin 125 $\mathrm{mg} /$ hari selama 4 minggu, didapatkan 76 subjek dengan hasil USG doppler arteri uterina yang menjadi normal dan 23 subyek tetap dengan hasil USG abnormal (20 orang tingkat I dan 3 orang ibu hamil tingkat III). Aspirin dosis rendah dapat menurunkan resistensi arteri uterina secara bermakna, dengan hasil $\mathrm{p}=0,0001$ $(\mathrm{p}<0,05)$.

Simpulan: Aspirin dosis rendah efektif untuk menurunkan resistensi arteri uterina yang abnormal pada ibu hamil usia kehamilan 16-24 minggu.
\end{abstract}

Kata kunci: ultrasonografi doppler velocimetry, resistensi arteri uterina, aspirin dosis rendah

\begin{abstract}
Objectives: to identify the effects of $125 \mathrm{mg} / \mathrm{day}$ aspirin on the reduction of uterine artery resistance in pregnant women of 16-24 weeks gestational age with abnormal uterine artery in USG doppler velocimetry.

Materials and Methods: This study is a pre-experimental of pretest post-testone group design. The subjects were pregnant women of Mulyorejo dan Kalijudan Surabaya health centers, gestational age of 16-24 weeks with the abnormal results of uterine artery doppler velocimetry. Uterine artery doppler ultrasound examination was carried out at the Department/SMF of Obstetrics Gynecology, Faculty of Medicine, Airlangga University-RSUD Dr. Soetomo, Feto-Maternal division, before and after the prescribed of aspirin $125 \mathrm{mg} /$ day for 4 weeks. Ultrasound examination of the uterine artery doppler velocimetry is divided into four grades; RI normal when $\leq 0.58$ without notching, grade I if $\mathrm{RI}>0.58$ without notching, grade II if $\mathrm{RI} \leq 0.58$ but accompanied by notching, and grade III if RI $>0.58$ accompanied by notching.

Results: 99 subjects of research with abnormal results of uterine artery doppler velocimetry; 81 of grade I, 2 of grade II, and 16 of grade III. From the results of uterine artery doppler velocimetry after the prescribed of aspirin $125 \mathrm{mg} /$ day for 4 weeks, it was obtained 76 subjects with normal results of uterine artery doppler ultrasound and 23 subjects remained with abnormal result of ultrasound (20 of grade I and three pregnant women with grade III). Low-dose aspirin may decrease uterine artery resistance was significantly, $\mathrm{p}=0.0001(\mathrm{p}<0.05)$.

Conclusion: Low-dose aspirin is effective to reduce abnormal uterine artery resistance in pregnant women with gestational age of 16- 24 weeks.
\end{abstract}

Keywords: doppler ultrasound velocimetry, uterine artery resistance, low dose aspirin

Correspondence: Rachmi, Departemen Obstetri dan Ginekologi, Fakultas Kedokteran, Universitas Airlangga, RSUD Dr Soetomo, J1 Prof dr Moestopo 6-8, Surabaya 60286

\section{PENDAHULUAN}

Preeklampsia masih menjadi ancaman serius di dunia kesehatan oleh karena berkonstribusi terhadap morbiditas dan mortalitas maternal dan perinatal. Angka kejadian preeklampsia diseluruh dunia berkisar antara 5\%-10\% ${ }^{1,2}$ Di Indonesia, lebih dari 30\% kematian ibu hamil pada tahun 2010 disebabkan oleh preeklampsia. Khususnya provinsi Jawa Timur, pada tahun 2012 angka kematian ibu hamil karena preeklampsia sebesar $34,88 \%$ meningkat dari tahun sebelumnya sebesar $27,27 \% .^{3}$

Preeklampsia merupakan "a disease of theory" dengan penyebab pasti yang masih belum diketahui, kegagalan remodelling arteri spiralis menyebabkan terjadinya kerusakan sel endotel pembuluh darah yang menyebabkan ketidakseimbangan produksi tromboksan A2 dan 
prostasiklin, mengakibatkan vasokonstriksi sistemik yang memberikan luaran kehamilan buruk terhadap ibu maupun janin seperti preeklampsia dan pertumbuhan janin terhambat (IUGR). Pemeriksaan ultrasonografi doppler velocimetry arteri uterina, merupakan suatu metode non invasif untuk mengetahui adanya perubahan tahap awal penurunan sirkulasi uteroplasenta, gambaran impedansi yang tinggi pada indeks resistensi $(\mathrm{RI}>0,58)$ pembuluh darah arteri uterina pada usia kehamilan 1624 minggu yang kadangkala disertai adanya notching pada awal diastolik menunjukkan tingginya tahanan pembuluh darah arteri uterina akibat vasokonstriksi pembuluh darah uteroplasenta. ${ }^{4,5}$

Aspirin dosis rendah (60-150 mg/hari) yang diberikan pada ibu hamil dengan USG doppler velocimetry arteri uterina abnormal merupakan salah satu metode untuk mencegah preeklampsia. ${ }^{6}$ Namun, beberapa hasil penelitian serupa menunjukkan hasil yang bervariasi. ${ }^{7,8}$ Pada penelitian ini, kami ingin mengetahui pengaruh pemberian aspirin $125 \mathrm{mg} /$ hari, yaitu tablet Asetosal $500 \mathrm{mg}$ dibagi menjadi empat bagian (tersedia di puskesmas) terhadap penurunan resistensi pembuluh darah arteri uterina pada ibu hamil USG doppler velocimetry arteri uterina abnormal usia kehamilan 1624 minggu.

\section{BAHAN DAN METODE}

Penelitian dilakukan di Departemen/SMF Obstetri dan Ginekologi Fakultas Kedokteran Universitas AirlanggaRSUD Dr. Soetomo, divisi Feto-Maternal mulai bulan Februari 2013-Juli 2015. Rancangan penelitian yang digunakan adalah pra-eksperimental pre-test and posttest one group design. Populasi dan subjek penelitian adalah seluruh ibu hamil usia kehamilan 16-24 minggu yang memeriksakan kehamilan di puskesmas Mulyorejo dan Kalijudan Surabaya.

Sedangkan yang menjadi sampel penelitian adalah semua ibu hamil usia kehamilan 16-24 minggu dengan hasil doppler velocimetry arteri uterina abnormal. Kriteria eksklusi adalah; kehamilan multifetal, adanya faktor risiko pada ibu (hipertensi dan diabetes) dan ibu hamil yang alergi dengan obat aspirin. Sedangkan untuk kriteria drop out, antara lain; subjek penelitian yang tidak datang untuk dilakukan pemeriksaan USG doppler velocimetry arteri uterina ulangan setelah mendapat aspirin $125 \mathrm{mg} /$ hari selama empat minggu, subjek penelitian yang saat dilakukan pemeriksaan doppler arteri uterina ulangan didapatkan janin IUFD dan subjek penelitian yang saat pemberian aspirin baru diketahui adanya tanda-tanda alergi atau kontraindikasi dengan obat aspirin.
Pemeriksaan dilakukan dengan alat USG GE tipe Voluson $730 \mathrm{~V}$ oleh sonographer yang berkualifikasi. Pemeriksaan dilakukan pada daerah lateral uterus kuadran bawah abdomen dengan membentuk sudut ke medial, untuk memudahkan terlebih dahulu dilakukan identifikasi arteri dan vena iliaka eksterna yang tersusun berdekatan secara paralel. Selanjutnya arteri uterina dapat diidentifikasi sebagai suatu pembuluh darah yang melintasi arteri iliaka eksterna. Pengukuran dilakukan dengan tetap memperhatikan sudut insonasi antara sinyal dari tranduser dengan pembuluh darah $\pm 45^{0} .9$ Proses yang sama dilakukan pada arteri kontralateral, hasil penilaian merupakan rata-rata dari kedua arteri uterina. Hasil pengukuran USG doppler velocimetry arteri uterina yang diperoleh diinterpretasikan sebagai berikut: Normal bila RI $\leq 0,58$ tidak didapatkan notching; Tingkat I bila RI > 0,58; Tingkat II bila RI normal + notching diastolik, dan Tingkat III bila RI > $0,58+$ notching diastolik.

Hasil USG abnormal (tingkat I, II dan III) diberikan aspirin $125 \mathrm{mg} /$ hari (tablet Asetosal $500 \mathrm{mg}$ dibagi 4 bagian) selama empat minggu. Kemudian dilakukan pengukuran ulang USG doppler arteri uterina pada subjek penelitian yang sama setelah intervensi selesai. Pemantauan pasien dilakukan dengan menghubungi pasien dan kunjungan ke puskesmas Mulyorejo dan Kalijudan. Data yang tercatat akan di analisis dengan menggunakan uji Wilcoxon Signed Rank. Penelitian ini telah disetujui oleh komisi etika untuk penelitian ilmu dasar/klinik di RSUD dr. Soetomo Surabaya/Fakultas Kedokteran Universitas Airlangga.

\section{HASIL DAN PEMBAHASAN}

Didapatkan 401 ibu hamil usia kehamilan 16-24 minggu yang dilakukan pemeriksaan USG doppler velocimetry arteri uterina, 295 ibu hamil $(73,56 \%)$ dengan hasil USG doppler yang normal dan 106 ibu hamil $(26,43 \%)$ dengan hasil USG doppler velocimetry arteri uterina abnormal, 1 ibu hamil dieksklusi karena diabetes pragestasional. Terdapat 6 orang ibu hamil yang tidak menyelesaikan penelitian (drop out) yaitu; 1 ibu alergi dengan obat aspirin, 1 ibu hamil di diagnosis diabetes gestasional dari hasil pemeriksaan TTGO 100 gram saat usia kehamilan 24 minggu dan 4 orang lainnya tidak datang untuk dilakukan pemeriksaan USG doppler ke II. Sehingga jumlah ibu hamil yang berhasil menyelesaikan alur penelitian yaitu sebanyak 99 orang.

Dari 99 orang ibu hamil setelah diberikan aspirin 125 $\mathrm{mg}$ /hari selama 4 minggu didapatkan; 76 (76,76\%) orang ibu hamil yang terjadi penurunan resistensi arteri uterina menjadi normal sedangkan yang tidak berubah atau masih tetap abnormal $23(23,23 \%)$ orang. 
Tabel 1. Karakteristik subyek penelitian

\begin{tabular}{lll}
\hline \multicolumn{1}{c}{ Karakteristik } & Frekuensi & $\%$ \\
\hline Variabel & & \\
$\quad$ Umur ibu (tahun) & & \\
$\quad<20$ & 3 & 3,9 \\
$20-35$ & 76 & 76,8 \\
$\quad>35$ & 20 & 20,2 \\
Gravida & & \\
$\quad$ Primigravida & 31 & 31,3 \\
$\quad$ Multigravida & 64 & 64,6 \\
$\quad$ Grande multigravida & 4 & 4,0 \\
Usia kehamilan (minggu) & & \\
$\quad<20$ & 37 & 37,4 \\
$\quad \geq 20$ & 62 & 62,6 \\
Indeks massa tubuh (kg/m) & & \\
$\quad<18,5$ & 7 & 7,1 \\
$18,5-24,9$ & 51 & 51,5 \\
$25,0-29,9$ & 23 & 23,2 \\
$\quad \geq 30$ & 18 & 18,1 \\
MAP (mmHg) & & \\
$\quad<80$ & 37 & 37,4 \\
$80-89,9$ & 53 & 53,5 \\
$90-100$ & 9 & 9,1 \\
\hline
\end{tabular}

Tabel 2. Sebaran hasil pemeriksaan USG doppler velocimetry arteri uterina dari 99 subjek penelitian

\begin{tabular}{lcc}
\hline $\begin{array}{c}\text { USG doppler } \\
\text { velocimetry }\end{array}$ & Frekuensi & $\%$ \\
\hline Tingkat-1 & 81 & $81,8 \%$ \\
Tingkat-2 & 2 & $2,0 \%$ \\
Tingkat-3 & 16 & $16,2 \%$ \\
\hline Total & 99 & $100 \%$ \\
\hline
\end{tabular}

Tabel 3. Perubahan resistensi arteri uterina sebelum dan sesudah pemberian aspirin $125 \mathrm{mg} /$ hari selama 4 minggu (uji Wilcoxon signed rank)

\begin{tabular}{|c|c|c|c|c|c|}
\hline \multirow{2}{*}{$\begin{array}{c}\text { Resistensi A. } \\
\text { ut }\end{array}$} & \multicolumn{3}{|c|}{ Sesudah } & \multirow{2}{*}{ Total } & \multirow{2}{*}{$p$} \\
\hline & normal & Tk. 1 & Tk. 3 & & \\
\hline \multicolumn{6}{|l|}{ Sebelum } \\
\hline$\overline{\text { Tingkat-1 }}$ & 66 & 14 & 1 & 81 & $<0,000$ \\
\hline Tingkat-2 & 1 & 1 & 0 & 2 & \\
\hline Tingkat-3 & 9 & 5 & 2 & 16 & \\
\hline Total & 76 & 20 & 3 & 99 & \\
\hline
\end{tabular}

Hasil uji statistik didapatkan nilai $\mathrm{p}<0,05$ yang berarti aspirin dosis rendah $125 \mathrm{mg} /$ hari signifikan menurunkan resistensi arteri uterina pada ibu hamil dengan USG doppler velocimetry arteri uterina abnormal usia kehamilan 16-24 minggu. Hampir 1/4 $(23,23 \%)$ ibu hamil dengan hasil USG doppler II yang masih abnormal setelah diberikan aspirin $125 \mathrm{mg} /$ hari, adapun faktorfaktor ibu yang mungkin mempengaruhi resistensi arteri uterina seperti; umur ibu, usia kehamilan, paritas, indeks massa tubuh (BMI) dan tekanan darah arteri rata-rata (MAP) telah kami lakukan analisis regresi logistik. Namun, tidak ada yang signifikan mempengaruhi hasil pemeriksaan doppler velocimetry arteri uterina pada hasil penelitian ini (Tabel 4).

Tabel 4. Analisis regresi logistik terhadap indeks resistensi arteri uterina sesudah pemberian aspirin $125 \mathrm{mg} /$ hari.

\begin{tabular}{|c|c|c|c|c|}
\hline \multirow{2}{*}{ Variabel } & \multicolumn{4}{|c|}{$\begin{array}{l}\text { Resistensi } \\
\text { arteri uterina }\end{array}$} \\
\hline & $\begin{array}{c}\text { Normal } \\
(\mathrm{n} 76)\end{array}$ & $\begin{array}{c}\text { Abnormal } \\
\text { (n 23) }\end{array}$ & $p$ & $\mathrm{R}^{2}$ \\
\hline 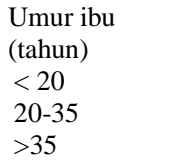 & $\begin{array}{c}3(3,9) \\
60(78,9) \\
13(17,1)\end{array}$ & $\begin{array}{l}0(0,0) \\
16(69,6) \\
7(30,4)\end{array}$ & 0,403 & 0,011 \\
\hline $\begin{array}{l}\text { Gravida } \\
\text { Primi } \\
\text { Multi } \\
\text { Grande }\end{array}$ & $\begin{array}{l}26(34,2) \\
47(61,8) \\
3(3,9)\end{array}$ & $\begin{array}{l}5(21,7) \\
17(73,9) \\
1(4,3)\end{array}$ & 0,612 & 0,004 \\
\hline $\begin{array}{l}\text { Usia kehamila } \\
\text { (minggu) } \\
<20 \\
\geq 20\end{array}$ & $\begin{array}{l}38(50,0) \\
38(50,0)\end{array}$ & $\begin{array}{l}13(56,5) \\
10(43,5)\end{array}$ & 0,953 & $<0,0001$ \\
\hline $\begin{array}{l}\text { IMT }(\mathrm{kg} / \mathrm{m})^{2} \\
<18,5 \\
18,5-24,9 \\
25,0-29,9 \\
\geq 30\end{array}$ & $\begin{array}{l}6(7,9) \\
41(53,9) \\
14(18,4) \\
15(19,7)\end{array}$ & $\begin{array}{l}1(4,3) \\
10(43,5) \\
9(39,1) \\
3(13,0)\end{array}$ & 0,848 & 0,001 \\
\hline $\begin{array}{l}\text { MAP }(\mathrm{mmHg}) \\
<80 \\
80-89,9 \\
90-100\end{array}$ & $\begin{array}{l}26(34,2) \\
42(55,3) \\
8(10,5)\end{array}$ & $\begin{array}{l}11(47,8) \\
11(47,8) \\
1(4,3)\end{array}$ & 0,097 & 0,043 \\
\hline
\end{tabular}

Sejak awal Februari 2013-Juli 2015 ( \pm 2,5 tahun), didapatkan $106 \mathrm{ibu}$ hamil usia kehamilan 16-24 minggu dengan hasil USG doppler velocimetry abnormal, satu ibu hamil kami eksklusi karena menderita diabetes dan 6 orang lainnya di drop out oleh karena; satu orang terjadi alergi, yaitu timbul gatal-gatal seluruh tubuh setelah minum obat aspirin, namun gejala membaik setelah pasien berhenti minum obat, satu ibu hamil di diagnosis diabetes gestasional dari hasil pemeriksaan TTGO 100 gram saat usia kehamilan 24 minggu dan 4 orang ibu hamil tidak datang untuk dilakukan pemeriksaan USG doppler ke II dengan berbagai alasan, seperti; pindah tempat kos, ingin melahirkan di desa atau tidak sempat periksa meskipun telah dihubungi ketika obat aspirin akan habis dalam waktu dekat. Dengan demikian pada penelitian ini didapatkan 99 orang subjek penelitian yang berhasil mengikuti penelitian hingga selesai. ${ }^{10}$ 
Ada beberapa faktor ibu yang merupakan faktor risiko untuk terjadinya preeklampsia seperti; umur ibu, paritas, dan indeks massa tubuh. Umur merupakan salah satu faktor penting terjadinya preeklampsia, usia ibu lebih dari 40 tahun meningkatkan hampir 2 kali risiko terjadinya preeklampsia $\left\{(1,96 \quad(1,34-2,87)\} .{ }^{11}\right.$ Pada penelitian ini usia ibu hamil yang paling muda adalah 16 tahun, sedangkan yang paling tua 42 tahun. Kemudian paritas, dari 99 ibu hamil dengan peningkatan resistensi arteri uterina, 31 orang $(31,3 \%)$ adalah primigravida dan 4 orang ibu hamil $(4,0 \%)$ merupakan grandemultipara. Sedangkan untuk obesitas yang merupakan faktor risiko definitif terjadinya preeklampsia, risikonya hampir 2 kali lipat pada ibu hamil dengan obesitas. ${ }^{10,11}$ Pada penelitian ini ada 18 orang ibu hamil $(18,1 \%)$ yang obesitas.

Terjadinya preeklampsia juga dapat dideteksi secara dini dengan menghitung mean arterial pressure (MAP), uji ini memiliki sensitifitas dan spesifisitas $93 \%$ dan $62 \%$, sedangkan ROT sensitifitas dan spesifitasnya sebesar 93\% dan 91\%. ${ }^{12}$ MAP positif atau MAP > 90 mmHg dikatakan 3,5 kali kemungkinan untuk terjadinya preeklampsia, dari karakteristik subjek penelitian ini kami dapatkan 9 orang ibu hamil $(9,1 \%)$ dengan MAP > 90 mmHg. ${ }^{11}$

\section{Hasil Pemeriksaan Resistensi Arteri Uterina}

Selama kehamilan normal, modifikasi hemodinamik menyebabkan penurunan tekanan darah, meskipun terjadi peningkatan curah jantung dan volume darah (faktor yang biasanya akan menyebabkan peningkatan tekanan darah). Penurunan tekanan darah dapat dijelaskan oleh karena terjadinya penurunan resistensi pembuluh darah perifer. Hal ini merupakan adaptasi tubuh ibu hamil untuk memenuhi kecukupan aliran darah ke uterus. ${ }^{13}$ Proses remodelling arteri spiralis yang sebagian besar telah terjadi setelah kehamilan 16 minggu, akan memudahkan pembuluh darah uteroplasenta untuk bervasodilatasi dan tidak mampu merespon zat-zat vasoaktif. Sehingga, resistensi pembuluh darah uteroplasenta juga akan berkurang, dengan demikian tidak mengherankan jika cukup banyak aliran darah ke uterus (uteroplasenta) untuk menjamin pertumbuhan janin dengan baik. ${ }^{14}$

Penurunan sirkulasi uteroplasenta salah satunya dapat diketahui dari pemeriksaan USG doppler velocimetry arteri uterina. Prinsip dari pemeriksaan USG doppler ini adalah kemampuan untuk mengidentifikasi berkurangnya aliran diastolik pada pembuluh darah arteri uterina sebagai penanda bahwa terjadi gangguan proses plasentasi pada pasien yang dilaporkan dapat berkembang menjadi pre-eklampsia dan IUGR, sehingga dapat digunakan untuk memprediksi pre-eklampsia dan
IUGR sebagai dampak dari insufisiensi aliran darah uteroplasenta. ${ }^{15,16}$ Resistensi yang tinggi pada arteri uterina dari pemeriksaan USG doppler terkait dengan gangguan migrasi trofoblas dalam miometrium dan perubahan fisiologis yang tidak memadai dalam arteri spiral pada wanita dengan preeklampsia dan IUGR yang dibuktikan dengan pemeriksaan histopatologi. ${ }^{17}$

Aspirin dapat mengganggu agregasi platelet dengan inaktivasi enzim siklooksigenase (COX) trombosit secara irreversible, sedangkan efek aspirin tergantung dosis pada sel endotel cepat memulihkan aktivitas COX sehingga kurang penting jika dibandingkan dengan efek antiplatelet didalam trombosit. Sehingga dikatakan pemberian aspirin dosis rendah dapat memperbaiki rasio PGI2 dan TXA2 menjadi relatif meningkat, menurunkan tahanan pembuluh darah dan memperbaiki sirkulasi uteroplasenta. ${ }^{18,19}$ Hal ini telah dibuktikan dengan pemberian aspirin dosis rendah (60-150 mg /hari) secara khusus menghambat produksi tromboksan tanpa mempengaruhi produksi prostasiklin. Analisis metabolit tromboksan (TBX2) dan prostasiklin (6-keto-PGF-1 $\alpha$ ) pada urine ibu, aspirin dosis rendah menurunkan metabolit tromboksan $61-87 \%$, sedangkan metabolit prostasiklin tidak berpengaruh. ${ }^{20}$

Aspirin dosis rendah $125 \mathrm{mg} /$ hari signifikan menurunkan resistensi arteri uterina pada ibu hamil dengan USG doppler velocimetry arteri uterina abnormal usia kehamilan 16-24 minggu ( $\mathrm{p}<0,0001)$, yaitu sebanyak 76 orang ibu hamil $(76,76 \%)$ hasil USG doppler yang menjadi nomal. Meskipun didapatkan 23 ibu hamil $(23,23 \%)$ dengan hasil USG yang masih tetap abnormal setelah diberikan aspirin dosis rendah, akan tetapi sebenarnya hanya ada 1 orang saja ibu hamil yang meningkat gradasinya (tingkat I menjadi tingkat III) dan 2 orang ibu hamil yang resistensi arteri uterinanya tetap tingkat III setelah diberikan aspirin $125 \mathrm{mg} / \mathrm{hari}$, sedangkan 20 orang ibu hamil $(20,2 \%)$ lainnya, gradasi resistensi arteri uterinanya menjadi menurun ataupun tidak meningkat menjadi tingkat yang lebih tinggi setelah diberikan aspirin dosis rendah $125 \mathrm{mg} / \mathrm{hari}$.

Hasil penelitian ini juga terlihat bahwa pada hasil USG tingkat III, hampir sebagian $(43,75 \%)$ tidak menjadi normal setelah diberikan terapi aspirin dosis rendah selama 4 minggu, hal ini mungkin sesuai dengan literatur yang menyebutkan peningkatan indeks resistensi yang disertai adanya notching menunjukkan tingkat gangguan aliran darah uteroplasenta yang berat dan paling berisiko untuk luaran kehamilan yang buruk. $^{21}$ Sedangkan hasil USG tingkat I, yaitu yang hanya disertai peningkatan indeks resistensi sekaligus merupakan hasil USG terbanyak pada penelitian ini $(81,81 \%)$ merupakan hasil USG yang paling mudah turun tingkatannya atau menjadi normal setelah diberi 
aspirin dosis rendah, hanya 15 ibu hamil $(18,51 \%)$ dari 81 orang yang tidak mengalami perubahan. Akan tetapi apakah sebagian besar penurunan resistensi arteri uterina tersebut sepenuhnya karena pengaruh aspirin dosis rendah? Hal ini sulit untuk kami jawab karena kelemahan pada penelitian ini tidak ada kelompok kontrol sebagai pembanding. Sehingga sangat mungkin penurunan resistensi arteri uterina yang diperoleh karena ada faktor lain yang ikut mempengaruhi seperti tablet kalsium yang juga diberikan pada subjek penelitian, asupan kalsium yang rendah dapat merangsang pelepasan hormon paratiroid atau renin, sehingga meningkatkan kalsium intraseluler di otot polos pembuluh darah yang menyebabkan vasokonstriksi, sehingga pada ibu hamil dengan kadar kalsium darah yang rendah pemberian suplemen kalsium dapat mempengaruhi otot polos pembuluh darah melalui cara yang berbeda dengan aspirin. ${ }^{22}$ Pada penelitian ini kami tidak memeriksakan kadar kalsium darah subjek penelitian kami. Selain itu mungkin saja dengan cut off RI 0,58 , ada yang dengan sendirinya menjadi normal tanpa diberikan aspirin dosis rendah, oleh karena peningkatan RI saja memiliki nilai positif palsu yang tinggi, kecuali bila disertai adanya notching akan meningkatkan nilai prediksi positif. ${ }^{23}$

Penelitian lain yang pernah dilakukan oleh Harrington dkk, menunjukkan pemberian aspirin dosis rendah (100 $\mathrm{mg} /$ hari ) selama empat minggu pada ibu hamil dengan USG doppler arteri uterina abnormal 17-23 minggu dapat menurunkan resistensi arteri uterina sebesar $45 \%$ hampir sama dengan hasil penelitian Kurdi, dkk pada usia kehamilan 19-21 minggu sebesar 43,4\%.7,24 Adapun beberapa faktor yang dapat membedakan masing-masing hasil penelitian tersebut antara lain; seperti usia kehamilan saat dilakukan penelitian, definisi USG doppler abnormal, dan juga perbedaan populasi yang diperiksa. ${ }^{5,25}$ Penelitian Harrington dkk, menyimpulkan aspirin dosis rendah signifikan dapat meningkatkan luaran kehamilan dengan mengurangi kejadian komplikasi yang terkait dengan insufisiensi uteroplasenta secara keseluruhan. $^{\text {? }}$

Pada penelitian ini, didapatkan $23,2 \%$ ibu hamil dengan resistensi arteri uterina tetap abnormal setelah diberikan aspirin dosis rendah, sehingga mungkin ada faktorfaktor lain yang mempengaruhi resistensi arteri uterina. Adapun faktor-faktor ibu yang mungkin mempengaruhi resistensi arteri uterina seperti; umur ibu hamil, usia kehamilan, paritas, indeks massa tubuh dan tekanan darah arteri rata-rata (MAP), tidak ada yang secara bermakna mempengaruhi resistensi arteri uterina pada penelitian ini (Tabel 4). Sebuah penelitian yang menganalisis gambaran USG doppler arteri uterina pada ibu hamil usia diatas dan dibawah 35 tahun, gelombang doppler arteri uterina trimester kedua tidak dipengaruhi oleh usia ibu. ${ }^{26}$ Sedangkan MAP signifikan mempengaruhi indeks resistensi (RI) dan protodiastolic notching pada bentuk gelombang arteri uterina, yaitu MAP > $100 \mathrm{mmHg}$, dimana peningkatan MAP yang disertai peningkatan resistensi arteri uterina memberikan luaran yang buruk untuk kehamilan. ${ }^{27}$ Selain itu, aspirin dosis rendah (60-150 mg/hari) signifikan menghambat produksi tromboksan sebesar $61-87 \%$, dimana aspirin tidak seluruhnya dapat menurunkan resistensi arteri uterina. ${ }^{20}$ Dengan demikian ada faktor-faktor lain atau faktor-X yang belum diketahui yang menyebabkan peningkatan resistensi arteri uterina tersebut tidak menurun setelah diberikan aspirin dosis rendah.

\section{SIMPULAN}

Aspirin dosis rendah $125 \mathrm{mg} / \mathrm{hari}$ yang diberikan selama empat minggu efektif untuk menurunkan resistensi arteri uterina pada ibu hamil dengan peningkatan RI yang merupakan risiko terjadinya preeklampsia.

\section{DAFTAR PUSTAKA}

1. Bolin M. Preeclampsia-possible to predict? A biochemical and Epidemiological Study of Preeclampsia. ACTA Universitatis Upsaliensis, UPPSALA. 2012.

2. Kayode $\mathrm{O}$ and Olusimbo K. Public health Prespectives of Preeclampsia in Developing Countries: Implication for Health System Strengthening. Hindawi Publishing Corporation Jurnal of Pregnancy. 2011.

3. Dinas Kesehatan Provinsi Jawa Timur. Profil Kesehatan Provinsi Jawa Timur. Diambil dari http://www.depkes.go.id/resources/download/profil /profil_kes_provinsi_2012/15_profil_kes.prov.jawa timur_2012.pdf. 2012.

4. Anthony $\mathrm{C}$ and Edward J. Uterine artery doppler flow studies in obstetric practice. Am J Obstet Gynecol. 2009.

5. Patrick FW, Arnott N, Owen P. How useful is uterine artery Doppler flow velocimetry in the prediction of pre-eclampsia, intrauterine growth retardation and perinatal death? An overview. BJOG. 2000;107(2):196-208.

6. Bujold E, Morency A, Roberge S. Acetylsalicylic Acid for the Prevention Of Preeclampsia and Intrauterine Growth Restriction in Women with Abnormal Uterine Artery Doppler: A Systematic Review and Meta-analysis. J Obstet Gynaecol Can. 2009;31(9):818-26.

7. Harrington K, Kurdis W, Aquilina J. A prospective management study of slow-release aspirin in the palliation of uteroplacental insufficiency predicted 
by uterine artery Doppler at 20 weeks. Ultrasound Obstet Gynecol. 2000;15:13-8.

8. Papageorghiou AT, Yu KH, Bindra R. Multicenter screening for pre-eclampsia and fetal growth restriction by transvaginal uterine artery Doppler at 23 week of gestation. Ultrasound Obstet Gynecol. 2001;18:441-9.

9. International Society of Ultrasound in Obstetrics \& Gynecology. ISUOG Practice Guidelines: use of Doppler ultrasonography in obstetrics. Ultrasound Obstet Gynecol. 2013;41:233-9.

10. Sibai BM. Diagnosis and Management of Gestasional Hypertension and Preeclampsia. Am Obstet Gynecol. 2003;102:475-7.

11. Carty M. Pre-eclampsia; early prediction and longterm consequences. University of Glasgow. 2012:21-30.

12. Cuningham F, Leveno K, Bloom S. Williams Obstetric. 24th Eds. McGraw Hill Education; 2014.

13. Philip NB and John CP. Pre-Eclampsia Current Perspectives on Management The Parthenon Publishing Group. 2004.

14. Roberts. Pathophysiology of ischemic placental disease. Seminars in Perinatology. 2014;3(8):13945.

15. Gomez, Figueras F, Martinez JM. Sequential changes in uterine artery blood flow pattern between the first and second trimesters of gestation in relation to pregnancy outcome. Ultrasound Obstet Gynecol. 2006;28:802-8.

16. Jeltsje S, Rachel K, Gerben. Use of uterine artery Doppler ultrasonography to predict pre-eclampsia and intrauterine growth restriction:a systematic review and bivariable meta-analysis. CMAJ. 2008;178(6):701-11.

17. Sagol S, Ozkinay E, Oztekin D. The Comparison of Uterine Artery Doppler Velocimetry with the Histopathology of the Placental Bed. Aust NZ J Obstet Gynecol. 1999;3:324-9.

18. Dekker G and Sibai BM. Low-dose aspirin in the prevention of preeclampsia and fetal growth retardation: Rationale, mechanisms, and clinical trials. Prevention of preeclampsia with low-dose aspirin. Am J Obstet Gynecol. 1993;168(1):214-27.

19. Zimmermann P, Eiri V, Koskinen J. Effect of low dose aspirin treatment on vascular resistance in uterine, uteroplacenta, renal and umbilical arteries-a prospective longitudinal study on a high risk population with persistent notch in the uterine arteries. Eur J of Ultrasound. 1997;5:17-30.

20. Walsh. Prostaglandins in Pregnancy. The Global Library of Women'sMedicine, Retrieved fromhttp://www.glowm.com/section_view/heading/ Prostaglandins\%20in\%20Pregnancy/item/314\#285 75. 2011.

21. Devore GR. Uterine Artery Measurements. Fetal Diagnostic Centers, Retrieved from, http://www.fetal.com/NT screening/10 uterine artery meas.html. 2014.

22. Villar J, Abdel-Aleem H, Merialdi M, Mathai M, Zavaleta $\mathrm{N}$, et al. World Health Organization randomized trial of calcium supplementation among low calcium intake pregnant women. Am J Obstet and Gynecol. 2006;194:639-49.

23. Giordano R, Romano AC. Uterine artery doppler flow studies in obstetric Practice. J Prenat Med. 2010;4(4):59-62.

24. Kurdi W, Fayyad A, Thakur V, Harrington K. Delayed normalisation of uterine artery doppler waveforms is not a benign phenomenon. Eur $\mathbf{J}$ Obstet Gynecol. 2004;117:20-3.

25. Guzman ER, Kontopoulos E, Zalud I. Doppler Velocimetry of the Uteroplacental Circulation. 2006; 16:243-5.

26. Chanthasenanont A, Nanthakomon T, Pongrojpaw D. Relationship between Maternal Age and Uterine Artery Doppler Flow during Second Trimester. Thai J Obstet Gynaecol. 2012;20:173-8.

27. Zimmermann P, Eiri V, Koskinen J. Effect of low dose aspirin treatment on vascular resistance in uterine, uteroplacenta, renal and umbilical arteries-a prospective longitudinal study on a high risk population with persistent notch in the uterine arteries. Eur J of Ultrasound. 1997;5:17-30. 